\title{
Path-Dependent High Cycle Fatigue Modeling of Joint Interfaces in Structural Concrete
}

\author{
Koichi Maekawa ${ }^{1}$, Naoyuki Fukuura ${ }^{2}$ and Masoud Soltani ${ }^{3}$
}

Received 17 May 2007, accepted 27 September 2007

\begin{abstract}
A high-cycle fatigue constitutive model for concrete joint interfaces is proposed and the direct path-integral scheme for RC-PC structures with junction planes is presented. Both cyclic pullout and the associated dowel action of reinforcing bars are formulated at a crack/joint section in terms of the relative displacement derivatives of a pair of joint planes. The proposed differential formula is verified by high cycle fatigue experiments of dowel bars and pullout of reinforcement crossing a joint in structural concrete. In conducting the direct path integral of the constitutive equations, a logarithmic time integration method is adopted so as to achieve highly accelerated computation with reasonable accuracy. The scheme is applied to the assembly of pre-cast pre-stressed concrete members with reinforced concrete joints for the purpose of life-cycle assessment. A mechanics-based discussion is presented of the different fatigue life observed in precast slabs with localized discrete joints and in monolithically constructed reinforced concrete, where dispersed cracking develops.
\end{abstract}

\section{Introduction}

The mechanistic nonlinearity of concrete structures can be represented by combining continuum solids with dispersed cracks and discrete joints at points where distinct localization develops (Okamura and Maekawa 1991). In general, smeared crack finite elements of 2D or $3 \mathrm{D}$ extent are allocated to structural members and joint interfaces connect different members to take into account the localized deformation accompanying steel pullout, transverse shear slip and opening/closure of the joints, as shown in Fig. 1. This study concentrates on the fatigue mechanics of reinforced concrete $(\mathrm{RC})$ joint interfaces and the computational simulation of structures under high cycle load repetition.

Okamura and Maekawa (1991) raised the basic scheme of RC joint interface to deal with the pullout of reinforcing bars from footing for seismic analyses of shear walls. To meet the challenge, the strain-slip relation of embedded deformed bars and the shear transfer modeling along rough cracks were incorporated. Here, the integrated formula of the local bond-slip-strain relation (Shima et al. 1987, Shin et al. 1988) was used with regard to pullout slip of steel at the crack plane. In addition, the contact density model for rough crack interfaces by Li et al. (1987) was built in the structural $\mathrm{RC}$ joint interface modeling. In view of the seismic performance of RC columns and shear walls, the basic

\footnotetext{
${ }^{1}$ Professor, Department of Civil Engineering, The University of Tokyo, Japan.

E-mail:maekawa@concrete.t.u-tokyo.ac.jp

${ }^{2}$ Senior Engineer, Taisei Corporation, Japan.

${ }^{3}$ Assistant Professor, Department of Civil Engineering, Tarbiat Modares University, Iran.
}

scheme was fairly verified through systematically arranged experiments. Afterwards, much effort has been directed to development of constitutive modeling of steel pullout, shear transfer and dowel actions (Maekawa et al. 2003) associated with local curvature of reinforcement (Qureshi and Maekawa 1996, Soltani and Maekawa 2007). In this study, the authors aim at extending theses scheme to structural fatigue under repeated service loads as well as seismic ones.

In the practice of structure design and maintenance, structural performance needs to be examined by simulating the total mechanistic process under combined specified loads. In this checking process, direct integration of the space-averaged path-dependent constitutive models is carried out for low-cycle seismic action as well as high-cycle fatigue action, as shown in Fig. 2 (Maekawa et al. 2006). This general scheme was initially constructed for smeared crack modeling (e.g., Collins and Vecchio 1982, Okamura and Maekawa 1991) with dispersed cracks in finite domains. In a similar way to its application to seismic analysis, it is expected that the scheme will also prove feasible for structural concrete with localized joint interfaces under fatigue loads. To verify this assumption, it is necessary to clarify the localized mechanics at the exact location of cracks or close to the interface. In particular, in this study on fatigue, the focus is on the bond pullout and dowel action of reinforcing bars at joints.

The fatigue simulation of structural concrete with interfaces is expected to be useful particularly for precast structures with and without pre-stressing. In such structures, the source of nonlinearity is chiefly the joint mechanism. In this study, the effect of loading conditions is the main interest, so moving wheel action is compared with the case of fixed point loading, with attention directed primarily at the contrast with 

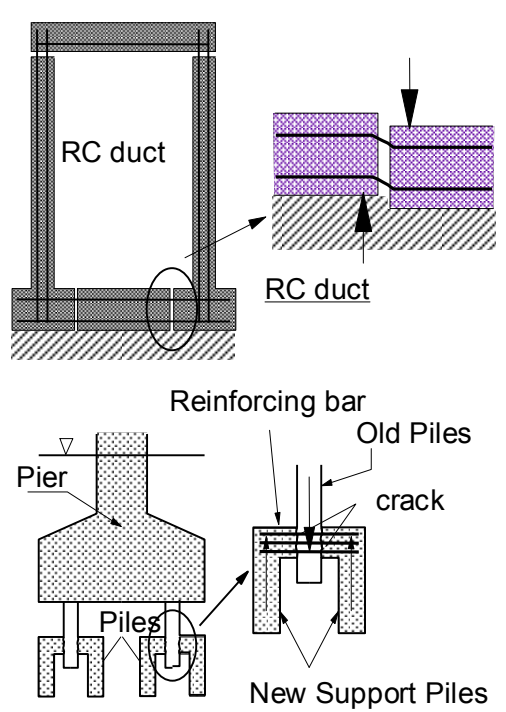

Support system for existing piles

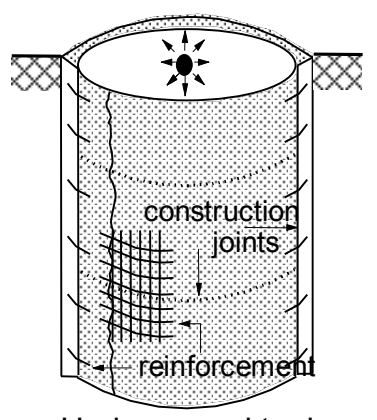

Underground tank

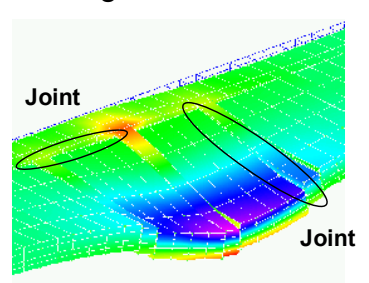

Assembly of precast slabs with joints (half-model)
Distributed crack

smeared element
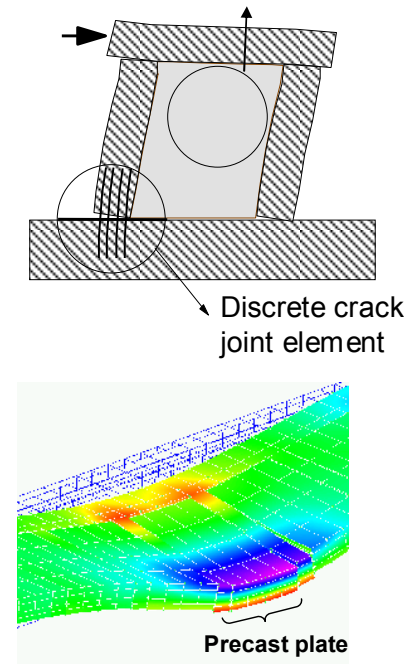

Precast plate

Fig. 1 Combination of smeared and discrete finite elements for structural concrete.
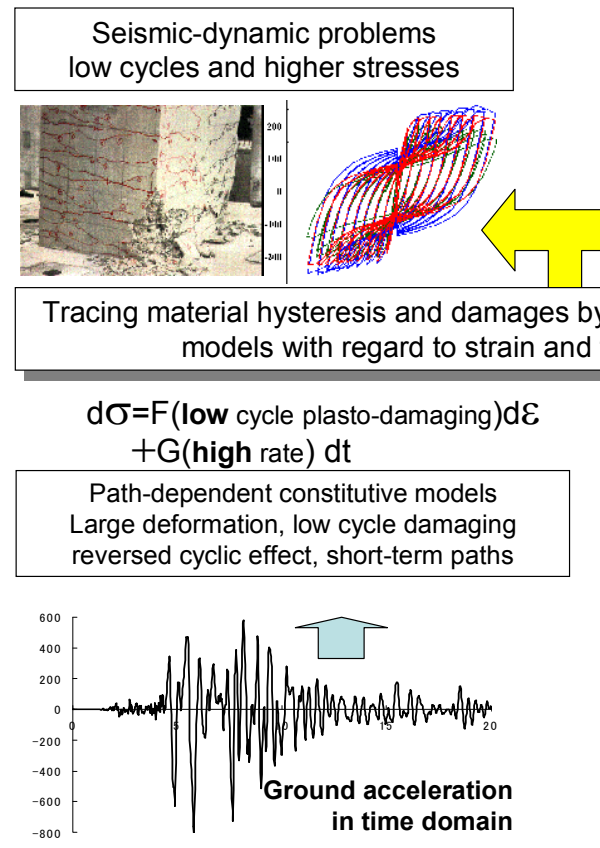

Fatigue-static problems high cycle and lower stresses

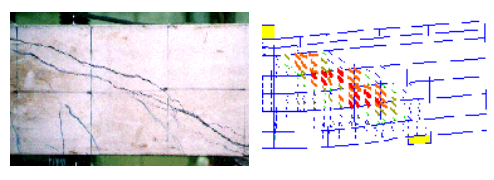

egrating rate-incremental constitutive

$\mathrm{d} \sigma=\mathrm{F}($ high cycle plasto-damaging $) \mathrm{d} \boldsymbol{C}$ $+\mathrm{G}$ (slow rate) $\mathrm{dt}$

Path-dependent constitutive models smaller deformation, high cycle damaging single sided, long-term paths with creep

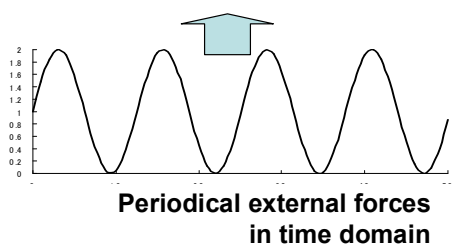

Fig. 2 Direct path-integral scheme for seismic and fatigue problems.

monolithically constructed RC slabs in which nonorthogonal multi-directional cracking is allowed.

\section{Basic formulation of $\mathrm{RC}$ joint interface}

The load-carrying mechanism of a RC joint interface consists of stress-transfer along concrete cracks or joint planes and the stress carried by reinforcement crossing the plane, as shown in Fig. 3. When the reinforcement is arranged normal to the joint, we have,

$$
\begin{aligned}
& \sigma=\sigma_{c}+p \cdot \sigma_{s} \\
& \tau=\tau_{c}+p \cdot \tau_{s}
\end{aligned}
$$

where, $(\sigma, \tau)$ is the total stress applied to the unit plane of the joint, $\left(\sigma_{c}, \tau_{c}\right)$ is the stress transferred by interlock 
or frictional contact between the pair of joint surfaces, $p$ is the reinforcement ratio, $\sigma_{\mathrm{s}}$ is the steel pullout stress and $\tau_{\mathrm{s}}$ is the dowel stress acting on the section of a single reinforcing bar. These stress components have been formulated under monotonic and cyclic action with a small number of repetitions in terms of joint opening, denoted by $\omega$, and shear slip along the joint, expressed by $\delta$. Opening " $\omega$ " is the section-averaged value having geometrical consistency with reinforcement pullout and is not exactly the same as the crack gap measured at the surface of the structure (Atimtay and Ferguson 1973), as shown in Fig. 3. In this chapter, the formulation is extended to cover high cycle fatigue.

\subsection{High cycle pullout of reinforcing bars}

Shima et al. (1987) found a unique correlation between local bond stress, bond slip and the steel strain as a point-wise constitutive law. Their formula was integrated over the embedded reinforcement and a unique relation between pullout slip of the reinforcement and the pullout force was mathematically and experimentally derived for sufficiently long embedment length. This formula was extended to more general conditions with bond deterioration zones close to joint planes (Okamura and Maekawa 1991, Maekawa et al. 2003) as,

$$
\begin{aligned}
& \omega=2 S \\
& s=\varepsilon_{s}\left(\beta+3500 \varepsilon_{s}\right) \\
& s=\frac{S}{D} K_{f c}, K_{f c}=\left(f_{c}^{\prime} / 20\right)^{2 / 3}
\end{aligned}
$$

where, $S$ is the pullout slip of the reinforcing bar, $s$ is the non-dimensional pullout slip, $f_{c}$ ' is the concrete compressive strength in $\mathrm{MPa}$, and $\beta$ is a nondimensional factor related to degree of bond deterioration close to the crack plane, with $\beta=2$ for no deterioration in an idealized case (Shima et al. 1987) and $\beta=6$ for normal bond deterioration of the $\mathrm{RC}$ joint interface. This factor has been adopted as the material constant for static and seismic analyses at low cycles. The symbol $\varepsilon_{\mathrm{s}}$ represents the steel strain at the joint, as shown in Fig. 3. Based on Eq. 2, the cyclic hysteresis loop was also formulated by Shima et al. (1987). This formula is now codified for calculating the ductility of $\mathrm{RC}$ members in the railway infrastructure.

However, the local bond gradually deteriorates with high cycling of the pullout forces and the strain of steel close to the free surface of the joint steadily increases, as shown in Fig. 4 (Yamada et al. 1991). The pullout slip is equal to the integrated strain profile over the reinforcement. In general, the local bond corresponding to the gradient of the strain profile is much reduced near the free end of the embedded bar, but it is almost

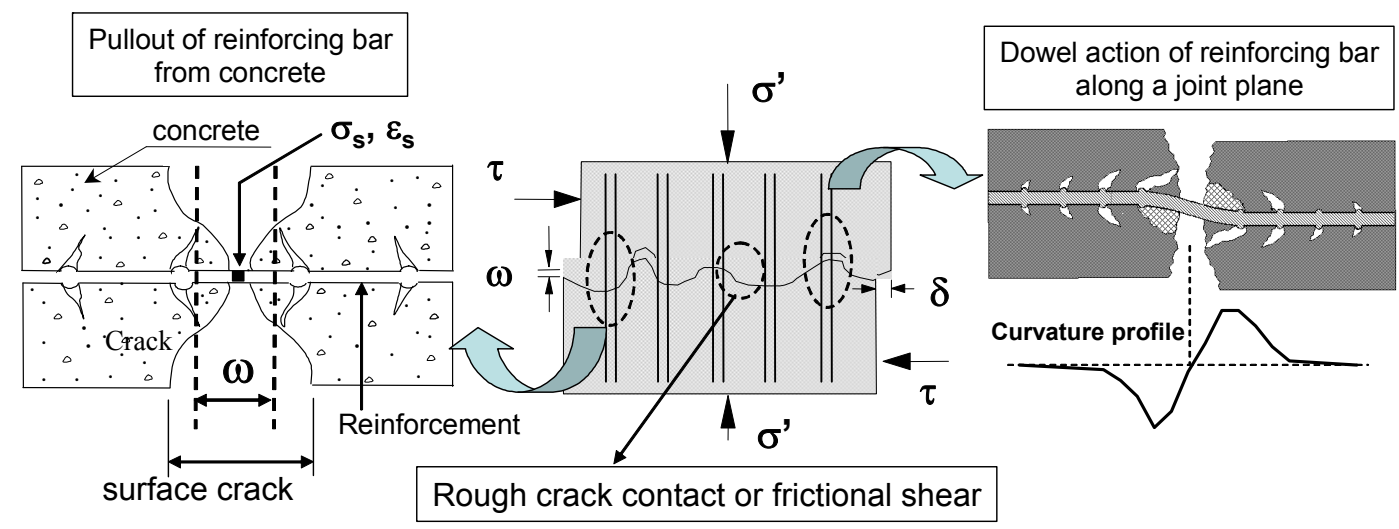

Fig. 3 Basic scheme for joint interface modeling.
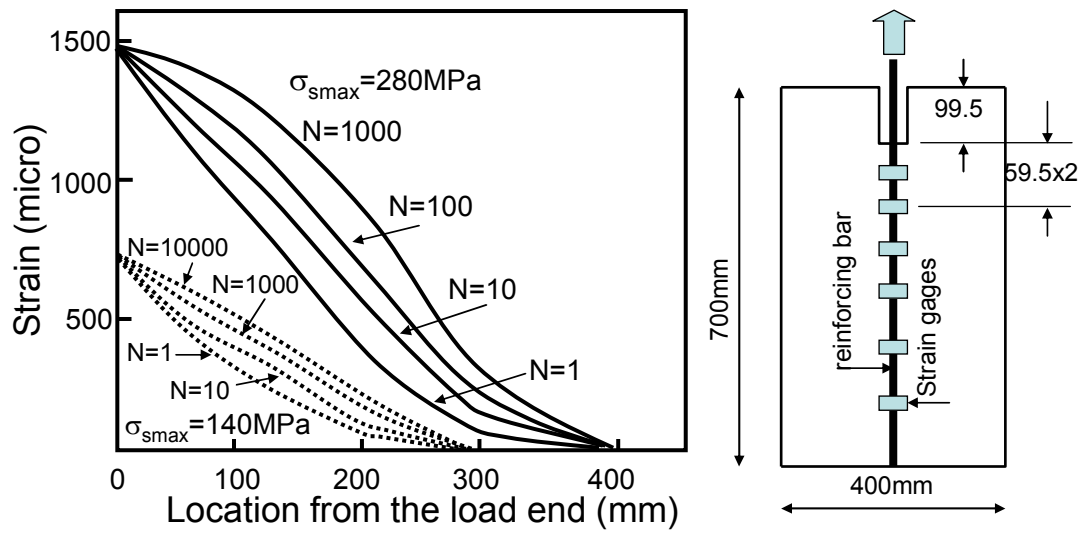

Fig. 4 Strain profiles along reinforcing bar under high cycle fatigue (Yamada, et al. 1991). 
constant inside the concrete. Roughly speaking, bond deterioration proceeds close to the joint surface, while interior bonding hardly changes.

In Fig. 5, the equivalent strain profiles are illustrated by dotted lines. These are shifted curves of the first loading cycle $(\mathrm{N}=1)$, and lead to the pullout displacement (integral of strain profile) corresponding to each number of cycle $(\mathrm{N})$. The shifted lines almost coincide with interior strain profiles along reinforcement under any number of fatigue loading cycles. Then, the drift of the shifted curves can be defined as the equivalent degree of bond deterioration. This implies that the original bond pullout model can be upgraded simply by modifying the parameter related to the degree of bond deterioration, that is to say, $\beta$ in Eq. 2 and Eq. 3.

The inversely identified increased bond deterioration for different load levels is also illustrated in Fig. 5. In general, the degree of damage evolution is nearly constant on the time-logarithmic scale. It is proportional to the stress applied at the extreme limit of pullout force. The authors therefore propose the fatigue model of bond deterioration as,

$$
\begin{aligned}
& \beta=\frac{\beta_{o}}{z}, \beta_{o}=6, z=0.5-0.05 \log _{10} G_{b}<1 \\
& G_{b}=\ln (10) \cdot \int \frac{m}{10^{m\left(s_{y}-\hat{s}\right)}} d \hat{s}, m=12 / s_{y}
\end{aligned}
$$

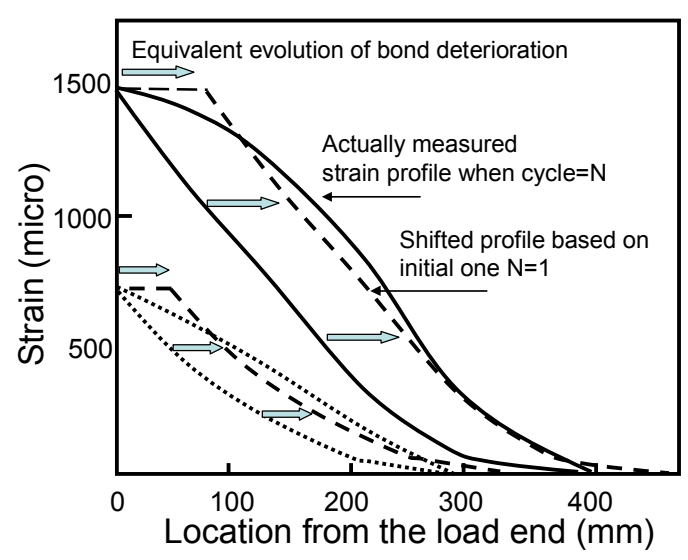

where, $s_{y}$ is the normalized yield pullout slip computed by Eq. (2) with $\varepsilon_{\mathrm{s}}=$ plastic yield strain, and $G_{b}$ is the damage index of bond deterioration. The differential unit denoted by $\hat{s}$ expresses the fatigue amplitude and its local origin is set at the turning point of pullout, as shown in Fig. 6. The consistency of the model with reality can be readily seen.

Application of the proposed model, as given by Eq. (3), is limited to the steel pullout at a single crack or joint plane connected to a massive concrete solid. For the case of a dispersed cracked domain, the fatigue tension stiffness model is available (Maekawa et al. 2006), as shown in Fig. 7. As this space-averaged tension-stiffness model incorporates delayed cracking due to fatigue and decay of the local bond, the two fatigue models cannot be compared directly. However, when loading is not that much above the cracking level (that is, when the crack spacing is large and the concrete between adjacent cracks can be assumed to remain stiff), the increased mean tensile strain predicted by the tension-stiffness model closely correlates with the local pullout predicted by Eq. (3).

Figure 7 shows the actual fatigue path from State $\underline{A}$ to State $\underline{B}$ over which the averaged crack spacing is thought to be stable. In this experiment by Nakasu and Iwatate (1996), the average strain increment from $\underline{A}$ to $\underline{\mathrm{A}^{\prime}}$ is about 0.0002 after 100,000 cycles. As the experimental crack spacing is nearly $200 \mathrm{~mm}$, the fatigue pullout from the concrete is approximately

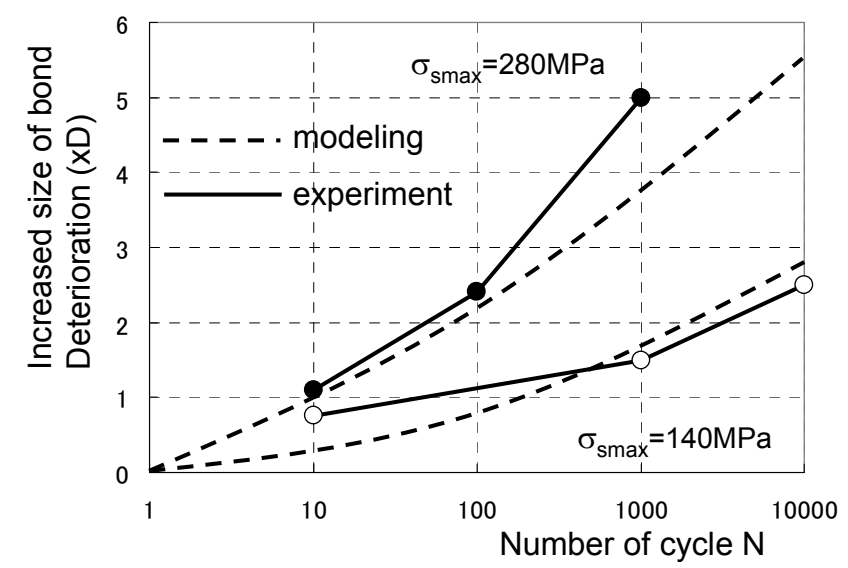

Fig. 5 Increased equivalent bond deterioration under fatigue loads.

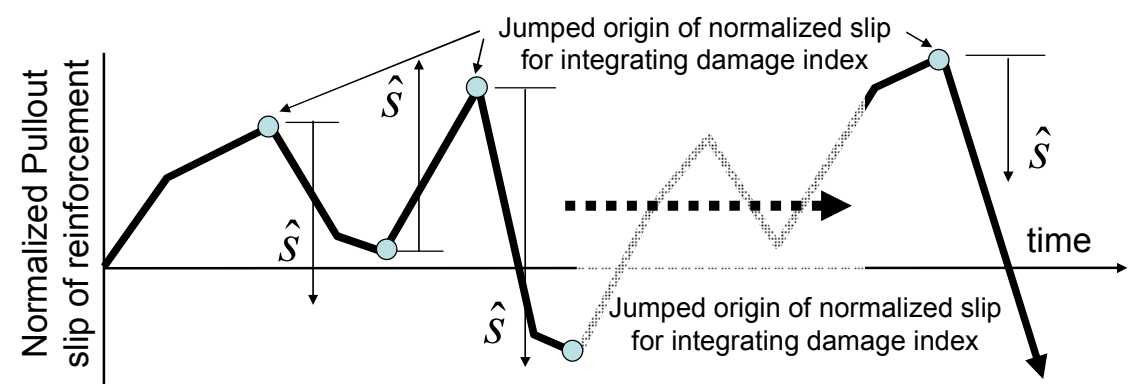

Fig. 6 Local pullout slip co-ordinates for integration of fatigue damage. 


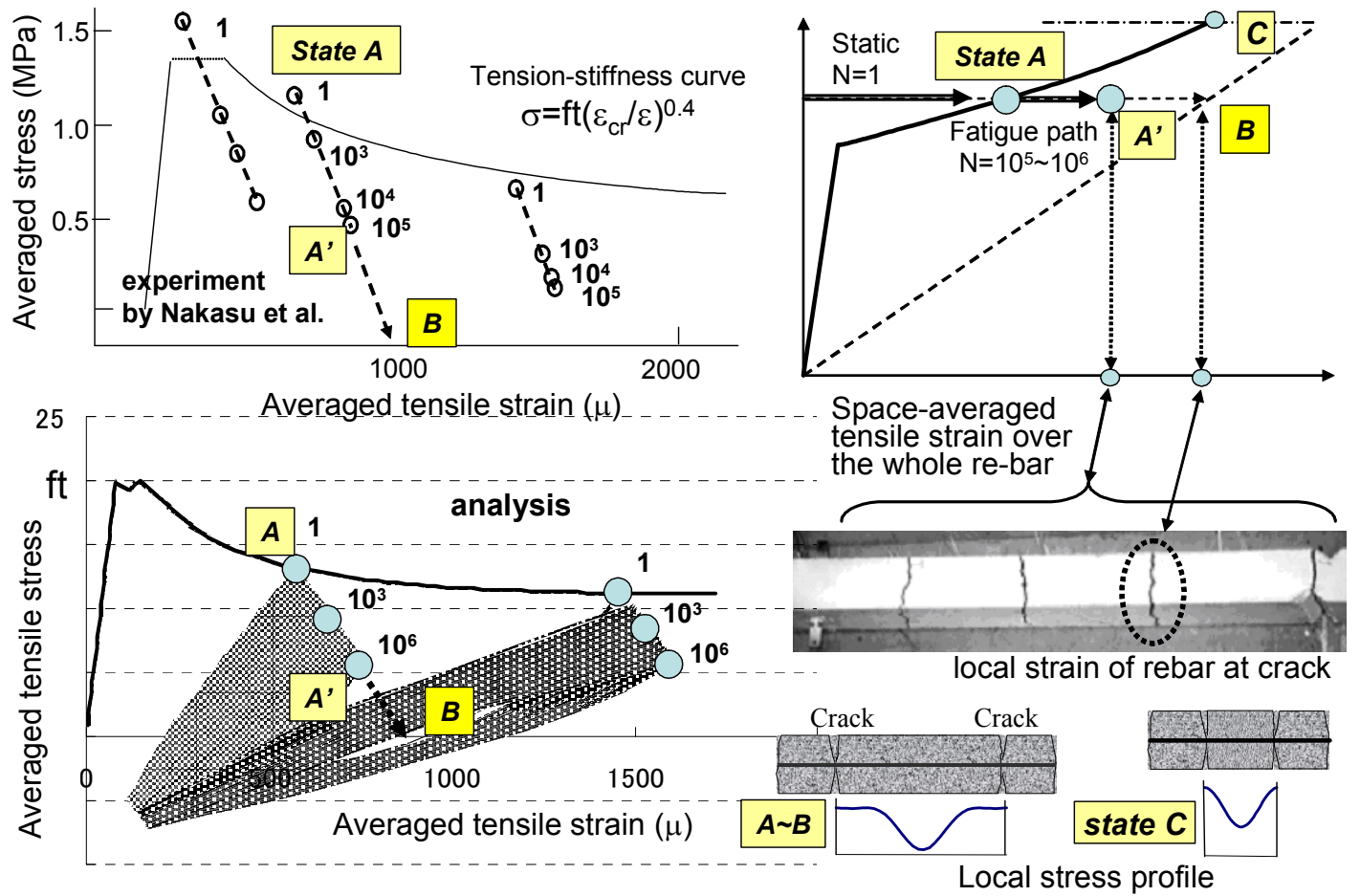

Fig. 7 Consistency with fatigue tension stiffness modeling (Nakasu and Iwatate 1996).

$200 \mathrm{~mm} \times 0.0002=0.04 \mathrm{~mm}$. As the maximum steel strain at the crack and the bar diameter are about 0.001 and $13 \mathrm{~mm}$, respectively, a unit deterioration in the bond causes $0.001 \times 13 \mathrm{~mm}=0.013 \mathrm{~mm}$ of pullout. Then, the increased bond deterioration normalized by bar diameter is about $3(0.04 / 0.013)$. Roughly speaking, this nearly matches the prediction also as shown in Fig. 5. Thus, the smeared crack approach in terms of tension-stiffness (Maekawa et al. 2006) and the discrete joint model presented in this study appear to be consistent in serviceability conditions.

\subsection{High cycle fatigue modeling of shear transfer}

Stress transfer through a pair of joint planes in contact with each other depends greatly on the microscopic structure of the planes. Frictional contact corresponding to rather flat planes is the most fundamental means of transfer and this mechanical property is represented mainly by the coefficient of friction (Tassios and Vintzeleou 1987). In this case, the shear dilatancy associated with shear slip can be ignored and perfect plasticity can be assumed, as illustrated in Fig. 8. As joint separation causes sudden loss of contact, the transferred shear is modeled to disappear in this situation. After re-contact, the transfer of shear stress begins again. This simple path-dependency is assumed for frictional contact planes in the structural analysis discussed in the latter section. It is suitable for application to direct contact between different material solids (e.g., Lotfi and Shing 1994). The effect of fatigue will be represented by a reduced coefficient of friction. Further, Carol et al. (1997) presented a softening model of the joint interface to describe the transient state of cracking. Here, the interaction of softened crack shear and gap opening is taken into account. In this study, a sudden jump from continuum to perfect separation is assumed for simplicity in the structural analysis.

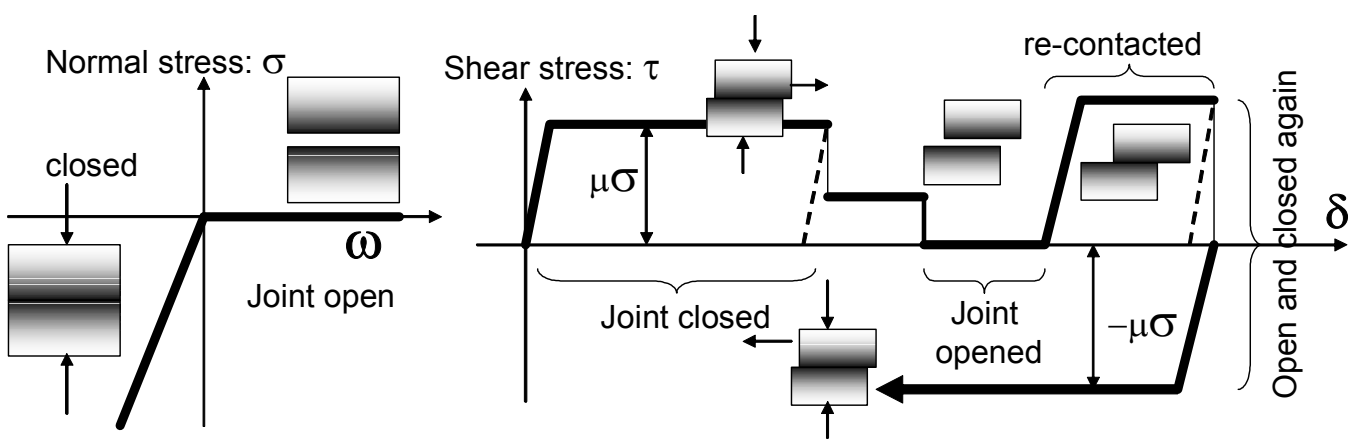

Fig. 8 Mechanism of frictional contact joint. 
Another practical case of stress transfer across joint planes is rough crack contact rooted in the interlocking of coarse aggregate particles. It is known that the shear transfer across rough crack planes degenerates under repeated slip, as shown in Fig. 9. Crack roughness and local contact friction are thought to be degraded after many cycles. According to the contact density model ( $\mathrm{Li}$ et al. 1987 and summarized in Fig. 9) which is based on Walraven's innovative analysis and modeling of rough cracks (1981), the transferred shear can be formulated in terms of intrinsic shear slip normalized by the crack opening (Maekawa et al. 2003). Pruijssers et al. (1988) investigated the fatigue damage evolution, and Gebreyouhannes (2006) carried out a fatigue experiment to determine shear transfer and associated dilatancy under medium loading levels, proposing the fatigue shear transfer model as formulated in Eq. (4). For the fatigue simulation of RC slabs without joints, this extended contact density formulation has been utilized within the framework of non-orthogonal multidirectional smeared cracks (Maekawa, et al. 2003, 2006).

$$
\begin{aligned}
& \tau_{c}=X \cdot \tau_{o r}(\delta, \omega), \quad \sigma_{c}=X \cdot \sigma_{o r}(\delta, \omega) \\
& X=1-\frac{1}{10} \log _{10}\left(1+\int d\left|\frac{\delta}{\omega}\right|\right), \quad \geq 0.1
\end{aligned}
$$

where, $\left(\tau_{\mathrm{or}} \sigma_{\mathrm{or}}\right)$ is the stress transferred by the concrete crack plane as calculated by the original contact density model and $X$ is the fatigue modification factor to express the stiffness reduction with regard to accumulated intrinsic shear deformation (Gebreyouhannes 2006). This formulation can be directly substituted into Eq. 1 with reinforcement pullout modeling. The effect of reversed cyclic paths on the accelerated damage evolution is also taken into account (Maekawa et al. 2006).

\subsection{High cycle fatigue of dowel action}

For normal rough cracks in concrete, the dowel action of reinforcing bars plays a minor role because of the significantly higher shear stiffness of crack joints with aggregate interlocking. For this reason, dowel action is generally ignored except where the reinforcement ratio is $6 \%$ or more. On the contrary, the dowel action of reinforcing bars becomes predominant if the interface planes are rather flat, such as in the case of construction joints and frictional interfaces between old and new concrete surfaces. For this reason, fatigue modeling of joints is required for structural simulation of pre-cast structures with lots of connection planes.

Monotonic and low cyclic models for dowel action have been proposed by Poli et al. (1992), Qureshi et al. (1996) and Soltani et al. (2007). These mechanistic models idealize the reinforcing bars as slender flexural beams of circular section that follow Euler-Kilchhof's

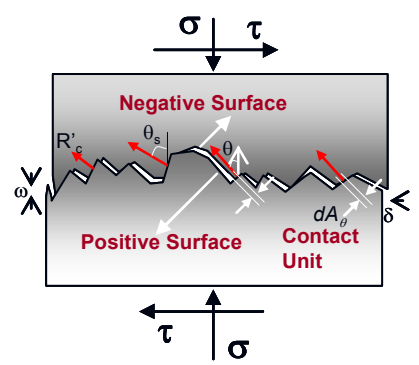

assembly of contact planes
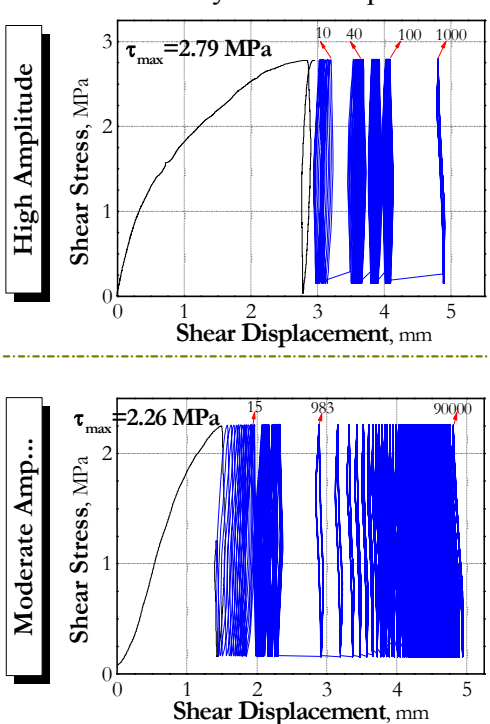
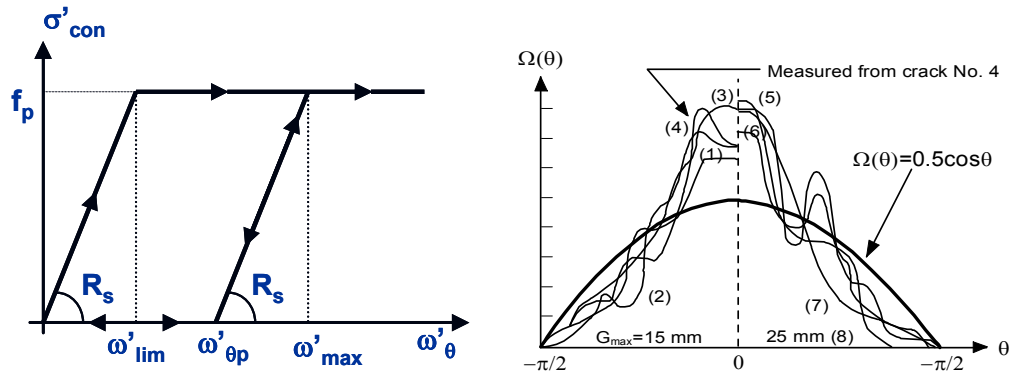

simplified contact stress-normal disp. relation contact density for crack shape
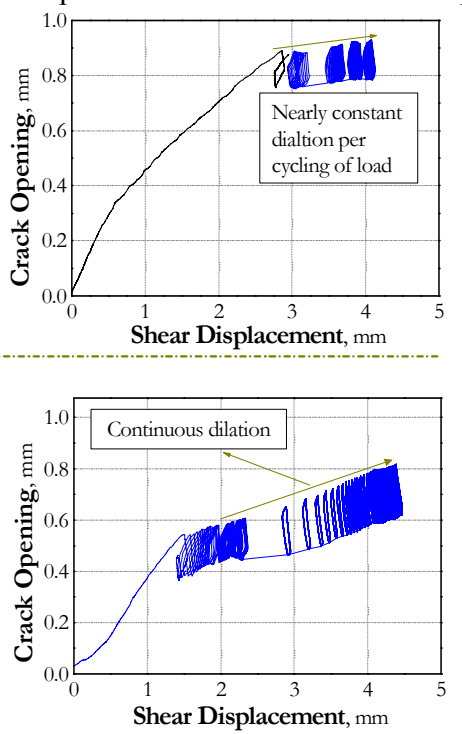

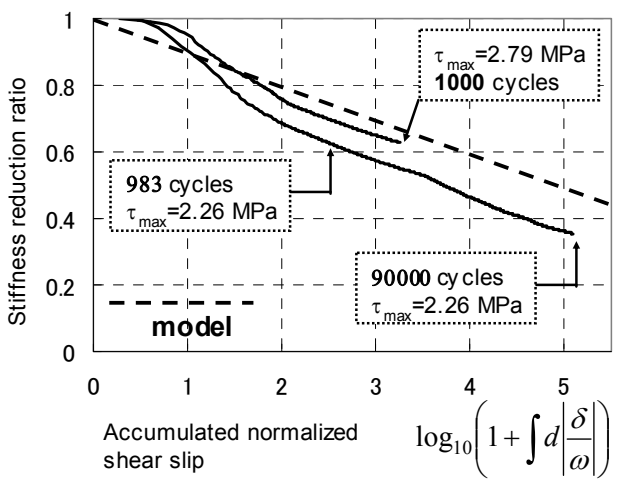

Fig. 9 Cyclic shear transfer stiffness and fatigue model (Li et al. 1987, Gebreyouhannes 2006). 
in-plane hypothesis and are transversely supported on a fictitious bed. Dowel action is then represented by the shear force at the joint location. Qureshi et al. (1997) proposed an intrinsic profile of curvature along the reinforcement and formulated the dowel force based on deformation compatibility in terms of pullout slip and transverse shear as,

$$
\tau_{s}=J(s, \delta)
$$

where, $s$ is the non-dimensional pullout slip defined by Eq. (2).

The dowel strength of bars is associated with local yielding within the concrete except in the immediate vicinity of the joint, because the extreme fiber stress of a section within the concrete reaches a maximum due to the large induced curvature. The section at the joint plane achieves the maximum axial force but the local curvature is zero. This means that dowel strength depends greatly on the diameter of the reinforcing bars, as shown in Fig. 10. A non-fatigue simulation and an experimental verification under reversed cyclic loading (Vintzeleou and Tassios 1987, Soroushian et al. 1988) were performed by Soltani et al. (2007), as shown in Fig. 10.

In order to investigate the mechanism of dowel action fatigue deterioration, a repeated single-sided shear force was applied to the flat plane across which a single deformed bar of $13 \mathrm{~mm}$ diameter was arranged, as shown in Fig. 11. First, a half length of the push-off specimen (Mattock and Hawkins 1972) was cast into the formwork. All sides were made with smooth form surfaces. One day after casting, the form was stripped and the second half length was immediately cast with additional forms attached to the already hardened concrete. This produced a flat shear plane and the applied shear force was carried only by the reinforcing bar. The compressive strength of the concrete was 40 $\mathrm{MPa}$ and the yield strength of the reinforcement was $395 \mathrm{MPa}$.

Three specimens with the same dimensions and materials were made and tested under different loading

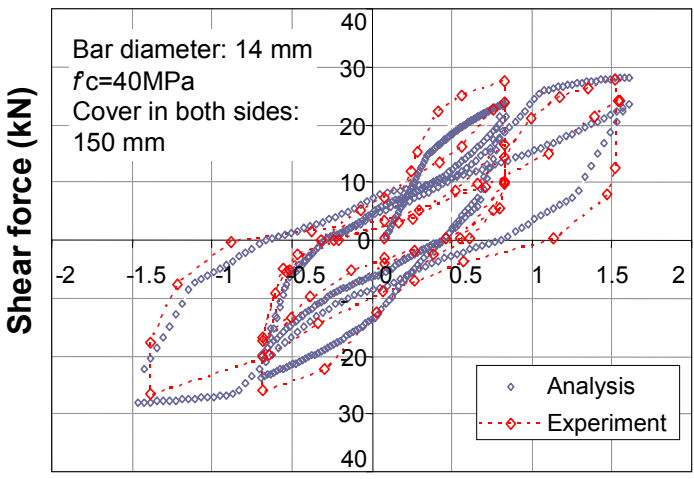

Dowel shear displacement $\delta(\mathrm{mm})$

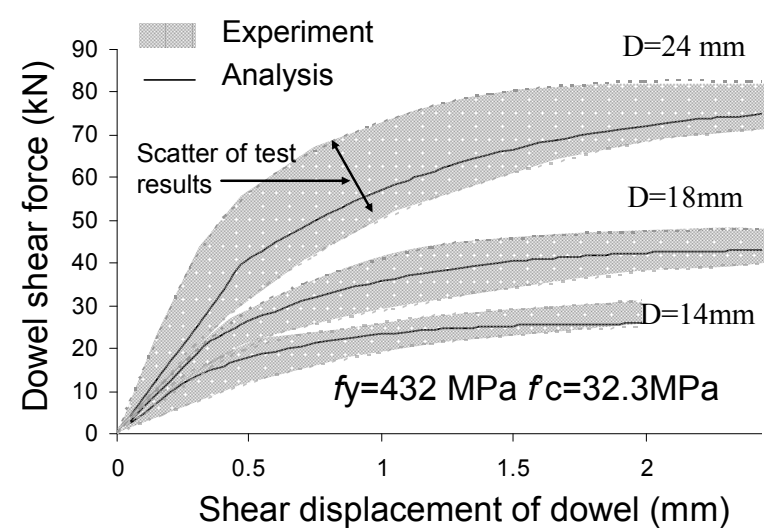

Shear displacement of dowel $(\mathrm{mm})$

Fig. 10 Low cycle dowel shear transfer of reinforcing bar.
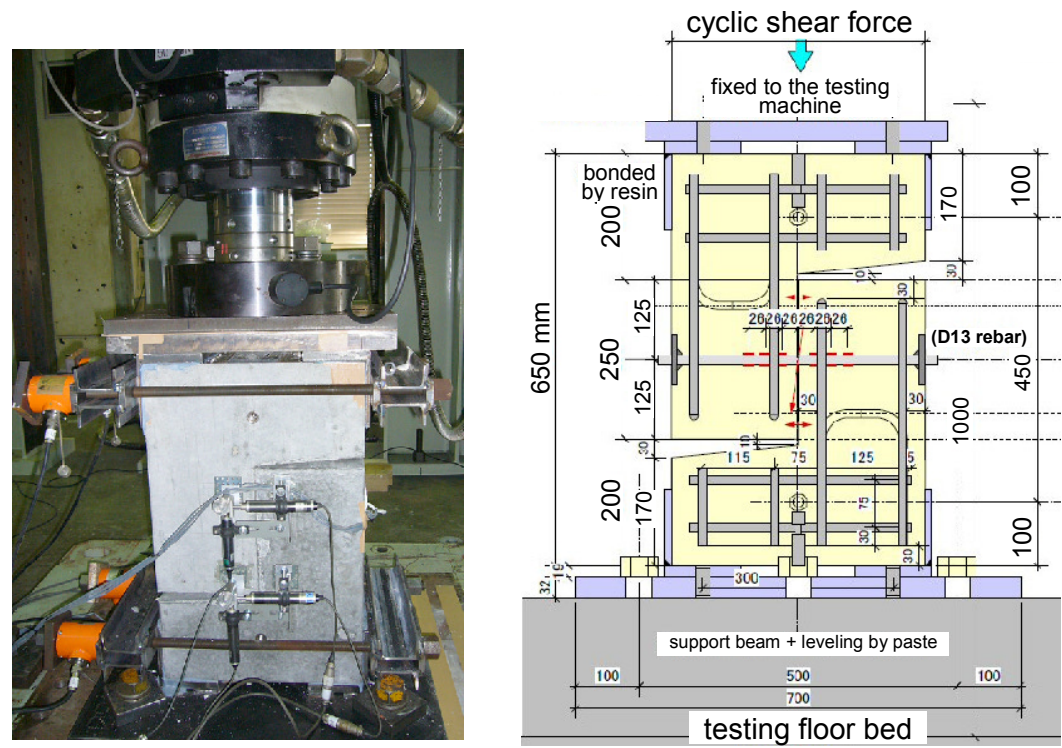

Fig. 11 Single-sided cyclic dowel shear experiment. 
levels. Specimen A was used to confirm the static capacity for dowel action. Specimens B and C were subjected to high cycle repetition of shear forces ranging up to $22.5 \mathrm{kN}$ and $11.0 \mathrm{kN}$, respectively. The minimum load level was set as $10 \%$ of the maximum shear force in order to keep the specimen stable without relaxation of the set-up under high cycle fatigue. The cyclic force was applied by means of a hydraulic servoactuator and the specimen was laterally supported to prevent out-of-plane collapse. Joint kinematics were measured by the use of non-contact transducers and the local strain of the reinforcing bar was picked up by strain gauges, as shown in Fig. 11. A pair of gauges were affixed to the bar surface upside down so that both local curvature and mean axial strain could be obtained. The integral of local curvature with respect to location should coincide with the dowel shear slip displacement (Maekawa, et al. 2003).

The experimental shear force versus slip displacement relation for Specimen A is shown in Fig. 12. After local yielding of the reinforcement (at about $30 \mathrm{kN}$ ), the dowel force gradually increased without showing a clear peak until the stroke capacity of the loading system was reached. The computed result matches the experiment fairly well, similarly to the verification by Maekawa et al. (2003) and Soltani et al. (2007).

Figure 13 indicates the relation between dowel shear force and transverse shear slip for Specimen B for various cycle totals. The shear slip increases as the number of cycles increases. The load level is high enough to induce considerable change in dowel shear; up to eight times the initial value. The residual dowel shear after release of the load also rises with the number of cycles. The incremental dowel shear is shown against the number of fatigue cycles in Fig. 14. There exists a linear relation between incremental dowel shear and the logarithm of the number of fatigue cycles. This is similar to the S-N diagram for the fatigue life of materials. The experimental result for Specimen $\mathrm{C}$ is shown together with that for Specimen B in Fig. 14. Although logarithmic linearity is clear in both cases, the

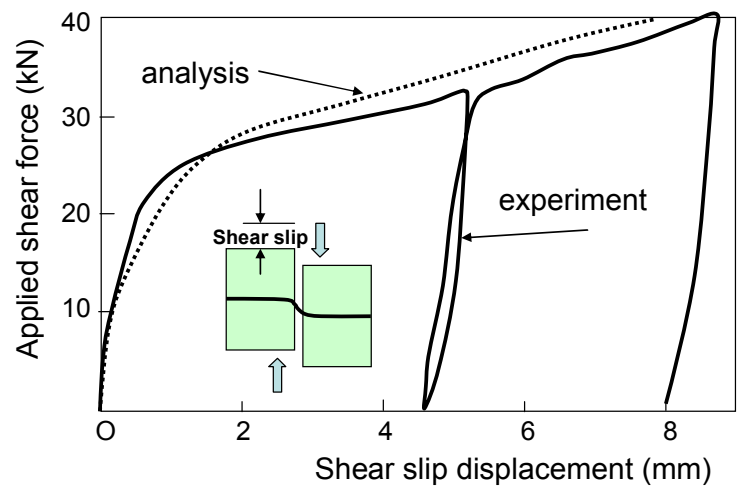

Fig. 12 Monotonic dowel shear force versus shear slip relation. rates of dowel shear evolution are very different.

Locally induced curvature at the location $2 \mathrm{D}$ from the joint plane is shown in Fig. 15. The experimental curvature was calculated by assuming a linear profile of fiber strains. Here, there is a clear linear relation between curvature and the logarithmic number of cycles and the rate of curvature change is found to depend greatly on the magnitude of amplitude. As the steel reinforcing bars continued to work without fatigue rupture, the experimental data can be used to verify the fatigue model of dowel action.

The increase in local curvature and dowel shear slip is thought to result from reduced transverse stiffness of the concrete supporting the reinforcing bars. Further, it has been reported that the deterioration of concrete surrounding steel bars is not very localized, unlike the case of fatigue pullout of reinforcement. In consequence, when longitudinal cracking occurs in the cover concrete, the confining stiffness of the concrete acting on the steel bars is more or less homogeneously reduced and a large amount of dowel shear displacement is caused. Then, the authors simply modify the original dowel action model described by $J$ in Eq. 5 in regard to fatigue deterioration as,

$$
\begin{aligned}
& \tau_{s}=J(s, \alpha \cdot \delta) \\
& \alpha=1.0-0.15 \sqrt{\log _{10}\left(1+G_{d}\right)} \\
& G_{d}=\frac{10}{D} \cdot \int|d \delta|
\end{aligned}
$$

where, $\alpha$ is a global stiffness reduction factor related to the accumulated damage denoted by $G_{d}$ as above. Since the dowel shear slip is equal to the integrated local curvature over the whole steel domain, its factorization
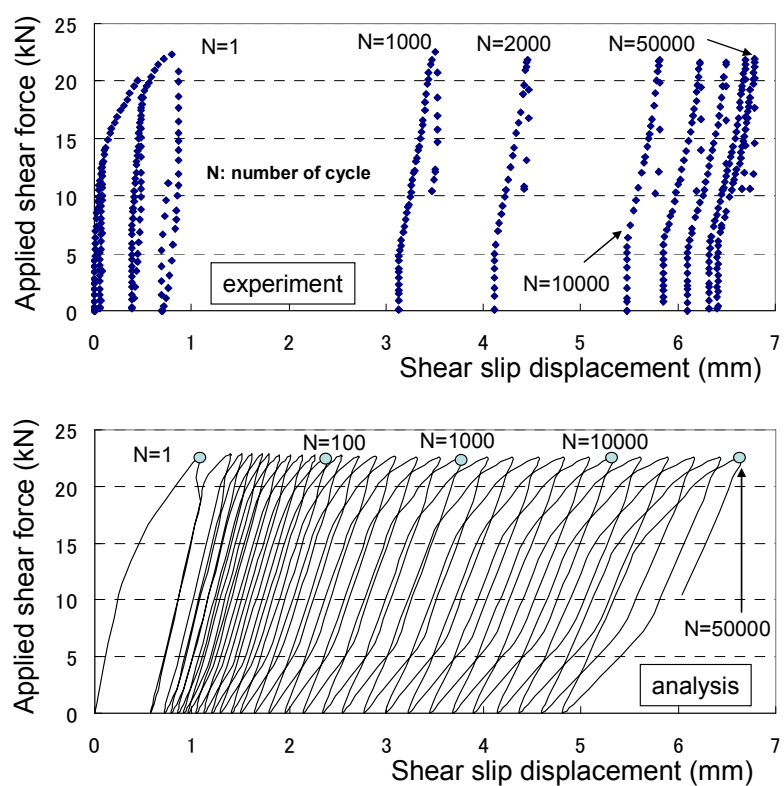

Fig. 13 Experimental high cycle fatigue dowel shear and simulation. 
implies a reduction in concrete stiffness to restrain the flexural deformation. For the present, this proposal should be limited to applications where the fatigue is single sided, although there is no mathematical constraint on its application elsewhere.

The computed relation between dowel shear slip and force is shown in Fig. 13 together with the experimental results. The incremental evolution of dowel shear is summarized in Fig. 14 for different amplitudes. It appears that reasonable agreement is obtained between simulation results and reality at the higher shear force amplitude $(22.5 \mathrm{kN})$, although the number of cases used for the verification is limited. In the case of lower amplitude $(11.0 \mathrm{kN})$, it seems that the predictive method gives rise to more rapid evolution of dowel fatigue than in reality (see Fig. 14). Here, it should be noted that the dowel displacement at the first cycle $(\mathrm{N}=1)$ is also overestimated a little, by about $10 \%$. This inevitably results in a larger accumulated shear slip based on the definition of $G_{d}$ in Eq. 6. In order to clarify sensitivity to this error, a slightly reduced force $(9.6 \mathrm{kN})$ was applied in the numerical model so that the displacement at the first cycle matches the experimental value. Fatigue evolution now follows the experiment reasonably and closely. This means that the discrepancy at the lower amplitude can be attributed to a slight overestimation by the original model, yielding a $\pm 10 \%$ discrepancy. The computed curvature, which is highly associated with dowel shear due to deformational compatibility, is also illustrated along with the experimental data in Fig. 15. Reasonable consistency is evident.

\subsection{Fatigue constitutive modeling of reinforcing bars}

In the path-integral scheme of fatigue simulation (Maekawa et al 2006), the stress or deformational amplitude is not necessarily constant in the modeling of dowel action and bond pullout. As a matter of fact, the local stress and/or strain amplitude of structural concrete vary even though the amplitude of externally applied forces is constant. Thus, the fatigue strength model for the steel has to be re-formulated to make it consistent with any stress or strain path. The tensile fatigue strength of a reinforcing bar, denoted by $f_{s r}$ (MPa), is specified in the JSCE code (2002) as,

$$
\begin{aligned}
& f_{s r}=190 \frac{10^{a}}{N^{k}}\left(1-\frac{\sigma_{s p}}{f_{u}}\right) \\
& a=k_{0 f}(0.81-0.003 \phi) \\
& k=0.12, k_{0 f}=1.0
\end{aligned}
$$

where, $N$ is the number of cycles and $\phi$ is the diameter of the reinforcing bar $(\mathrm{mm})$. Symbol $\sigma_{s p}$ means the lower bound stress related to permanent loads and $f_{u}$ is the tensile strength $(\mathrm{MPa})$. This formula derives from the S-N diagram of fatigue test data, which was
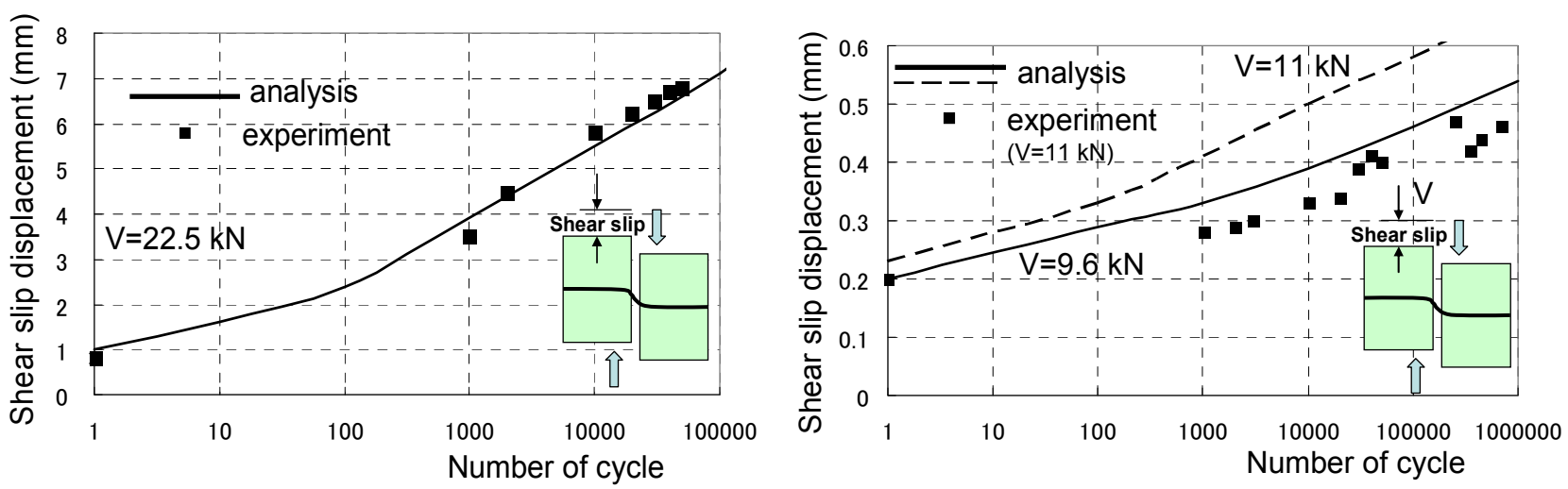

Fig. 14 Incremental dowel shear slip under high cycle fatigue.
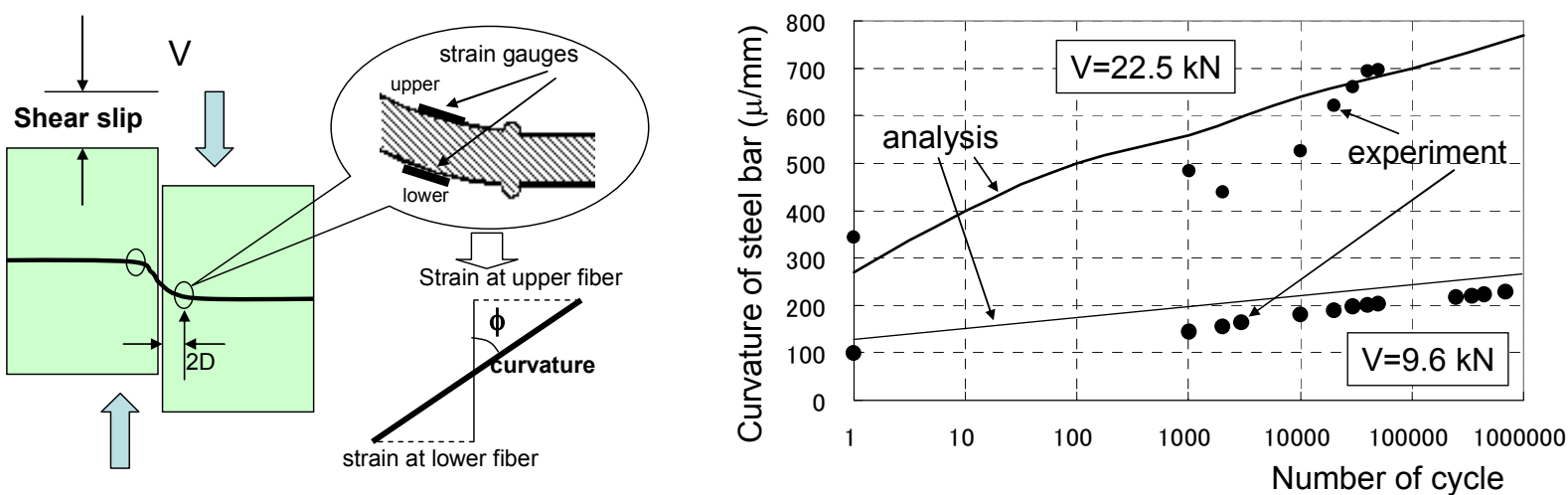

Fig. 15 Flexural curvature evolution of reinforcement associated with dowel shear. 
generally obtained under constant stress amplitude.

By following the concept of Palmgren-Miner's rule (the linear damage assumption, Palmgren 1924), this empirical formula can be converted into a discrete ratetype one so that the fatigue rupture of steel can be consistently monitored in the strain path-integral scheme as,

$$
\begin{aligned}
& D_{s}=\sum \frac{1}{N}=\sum\left[190 \frac{10^{a}}{\Delta \sigma_{s}}\left(1-\frac{\sigma_{s p}}{f_{u}}\right)\right]^{-1 / k} \\
& D_{s}=\frac{190 \cdot 10^{\alpha}}{k} \int\left(1-\frac{\sigma_{s p}}{f_{u}}\right)^{-1 / k} d \sigma_{s} \\
& D_{s}=1 \text { : fatigue failure, } D_{s}<1: \text { no failure }
\end{aligned}
$$

where, $D_{s}$ represents the accumulated damage related to fatigue rupture of the steel and $\Delta \sigma_{\mathrm{s}}$ is the stress amplitude as shown in Fig. 16. When the value of $D_{s}$ reaches unity, rupture of the reinforcement is inferred.

\subsection{Accelerated time-integral of fatigue constitutive modeling}

It has been shown that well-established methods of nonlinear dynamic analysis for RC structures can be extended to cover fatigue analysis in the time-space domain by direct path-integration of constitutive models (Maekawa et al. 2006). The essence of this extension is the material modeling, as explained in the previous sections. The fatigue effects of bond pullout, dowel action and shear transfer are simply incorporated into the original models in terms of evolution derivatives, so the resulting extended material models also cover highly nonlinear behavior. Consequently, the fatigue analysis system shares the same scheme as that for nonlinear failure analysis under seismic loading.

Repeated loading with high cycles can be represented as a direct input of nodal forces in full time steps. However, computation is excessive when large numbers of cycles are specified. To accelerate the computation, the logarithmic time derivative can be used in path integrating the constitutive models. The damaging rates with respect to deformational paths are simply integrated in the numerical scheme as,

$$
G_{b}=\ln (10) \cdot \int \frac{\zeta \cdot m}{10^{m\left(s_{y}-\hat{s}\right)}} d \hat{s}
$$

$\uparrow$ generalized bond pullout of Eq. 3

$$
X=1-\frac{1}{10} \log _{10}\left(1+\sum \zeta \cdot \Delta\left(\frac{\gamma}{\varepsilon}\right)\right), \geq 0.1
$$

$\uparrow$ generalized crack shear transfer of Eq. 4

$$
G_{d}=\frac{10}{D} \cdot \int \varsigma \cdot|d \delta|
$$

$\uparrow$ generalized dowel action of Eq. 6

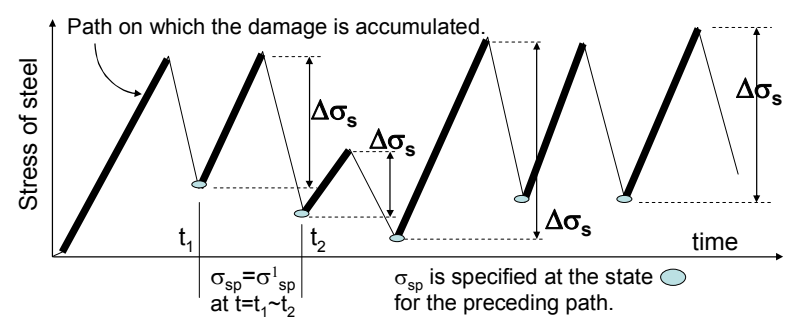

Fig. 16 Definition of stress amplitude and effective path for integrating steel damage.

$$
D_{s}=\frac{190 \cdot 10^{\alpha}}{k} \int \varsigma \cdot\left(1-\frac{\sigma_{s p}}{f_{u}}\right)^{-1 / k} d \sigma_{s}
$$

$\uparrow$ generalized steel tension fatigue of Eq. 8

where, $\zeta$ is the integral accelerator (Maekawa et al. 2006).

Material nonlinearities in structures develop rapidly at the beginning of fatigue loadings, so the value of $\zeta$ should be unity for accuracy. That is, the exact direct paths of forces and corresponding internal stresses should be tracked on the real time scale. After many cycles, plasticity, damaging and fatigue development tend to be much reduced and the increment in nonlinearity per cycle becomes exponentially small. At this stage, the value of $\zeta$ can be larger for computational efficiency at each load step. A single cycle of computational load is equivalent to $\zeta$-cycles. In Eqs. 912 , time and strain path integrals only are magnified by $\zeta$, but it should be noted that the terms of instantaneous nonlinearity associated with evolution boundaries (plasticity and damage) are not magnified by $\zeta$, but the path is strictly mapped out.

Figure 17 shows the computed displacement histories of an RC member with a discrete joint, as shown in Fig. 18. Details of this member are given in the following section. The thin (green) line represents analysis in which direct integration of fatigue constitutive models was carried out up to 1,000 cycles. Here, the magnification factor was kept at unity over the whole loading path. The broad (black) line is the computed result based on the magnified integral. The factor $\zeta$ for the $1^{\text {st }}$ cycle is unity and the $2^{\text {nd }}$ cycle corresponds to $\zeta=2$, the $3^{\text {rd }}$ to $\zeta=5$, the $4^{\text {th }}$ to $\zeta=10$ and so on. Just a few substantial cycles are enough to simulate the material and structural states with reasonable computational accuracy, as shown in Fig. 17. The equivalence of the magnification method to the exact path-integral has already been examined for monolithic RC members (Maekawa et al. 2006), so this demonstrates that a general analysis domain with or without a joint interface can be dealt with by the logarithmic time-integral method. 


\section{Verification and applicability in practice}

In general, the reliability of nonlinear modeling has to be crossways-examined at different levels; that is, verification is necessary not only at the material level but also at the member or structural level. In this chapter, the fatigue behavior of RC beams with a single joint interface is simulated to check the accuracy of material modeling under non-uniform fields of stress and deformation. Second, the proposed finite element computation method is applied to more realistic structures whose nonlinearity is chiefly rooted in joint interfaces. Here, slabs of PC-RC assembly under fatigue loading are selected for assessing the practical performance of the proposed method. For continuous zones of reinforced concrete domains, multi-directional non-orthogonal smeared crack modeling, which has been verified under high cycle fatigue loads (Maekawa et al. 2006), is applied.

\subsection{Joint interface connecting pre-cast RC panels}

A mixed structural member consisting of two pre-cast PC panels connected by $\mathrm{RC}$ joints is selected for experimental verification, as shown in Fig. 18. This is a full-scale mock-up of part of the extended runway for Tokyo International Airport at Haneda. External loading sets up a combined flexure moment and shear force. Since this target for experimental verification consists of a statically determinate structure subjected to a constant amplitude of external forces, the resultant amplitude of these sectional forces becomes constant. However, the local stress conditions along the joint interface are not uniform but vary from tension to compression. Thus, this structure is appropriate for verifying the fatigue model in more general stress states. The joint is divided into six elements as shown in Fig. 18.

The junction between the PC panels at the RC connection core is not a rough crack plane but a construction joint. The surface was artificially processed by abrasion to produce some amount of friction at closure. The simulation was then carried out with frictional contact, as shown in Fig. 18, and the frictional coefficient at closure was set equal to 0.5 according to past experience with concrete-to-concrete contact (Tassios and Vintzeleou 1987). The experimental and analytically obtained deflections and crack widths at the level of the tension reinforcement are shown in Fig. 18 at the $1^{\text {st }}$ and 2 millionth cycles. The magnified time integration, similar to the case shown in Fig. 17, is defined below.

The computationally predicted deflection matches the experimental measurements, but the crack width is slightly underestimated. The experimentally obtained crack width is a value measured at the surface of the concrete member, while the computational value is the average crack width at the level of the tension reinforcement (see Fig. 3). In fact, the physical crack gap right on the surface of the reinforcing bars is known to be almost nil; local crack width increases proportionally according to location, as illustrated in Fig. 3. For this reason, a slight underestimation is thought to be reasonable in view of the mechanical model of bond pullout. In this experiment, the shear slip along the joint plane was not the same in experiment and analysis.

\subsection{Pre-cast slab system under moving wheel- type loads}

The stress state of the mock-up specimen discussed in the previous section is, on the whole, two-dimensional. In this section, the verification is extended to more generic three-dimensional states. Figure 19 shows a laterally supported slab system consisting of PC pre-cast panels and RC block connectors. The slab system is longitudinally supported through the joint interfaces linking the main body of the PC panels to the RC connectors, as shown in Fig. 18. A traveling wheel load is applied repeatedly to produce three-dimensional stress states accompanying principal stress rotation. This verification of the simulation scheme is focused on dowel action and bond pullout, so shear transfer along the joint plane is intentionally neglected by defining zero as the friction coefficient. Only normal compression is transferred at contact and it is assumed that no tension is transferred at all.

Figure 20 shows the simulation results, in which no external membrane force is applied but out-of-plane bending and shear are produced. The computational traveling load is $800 \mathrm{kN}$ and the corresponding deflection at the center of the slab, the tension reinforcement stress and the contact stress at the compressive extreme fiber are shown for the central joint plane. The magnified logarithmic time integral is the same value as adopted in the previous section. A gradual progressive deflection can be seen in the results and transverse shear slip is not insignificant, since shear transfer is unrealistically ignored so as to obtain a functional check of dowel action and steel pullout under fatigue action. Similar magnitudes of incremental shear slip at the joint and of structural deflection are obtained. Since the pre-cast panels are free from cracking due to pre-stressing numerically induced in terms of initial strain, the main source of nonlinearity derives from the joint interfaces.

The maximum joint opening at the tension reinforcement is almost constant over the load history. A gradual decay of steel tensile stress is seen, as shown in Fig. 20. This means that the embedded reinforcement exhibits reduced pullout stiffness; this is caused by evolving bond deterioration close to the joint plane. As a result, the bending moment shifts from joint areas to the pre-cast panels and the flexural tension at the bottom face of the slabs gradually increases. As the decay in joint stiffness reduces the subsequent risk of reinforcement fatigue failure at the joint, the initial stress amplitude of steel can be used for fatigue design 

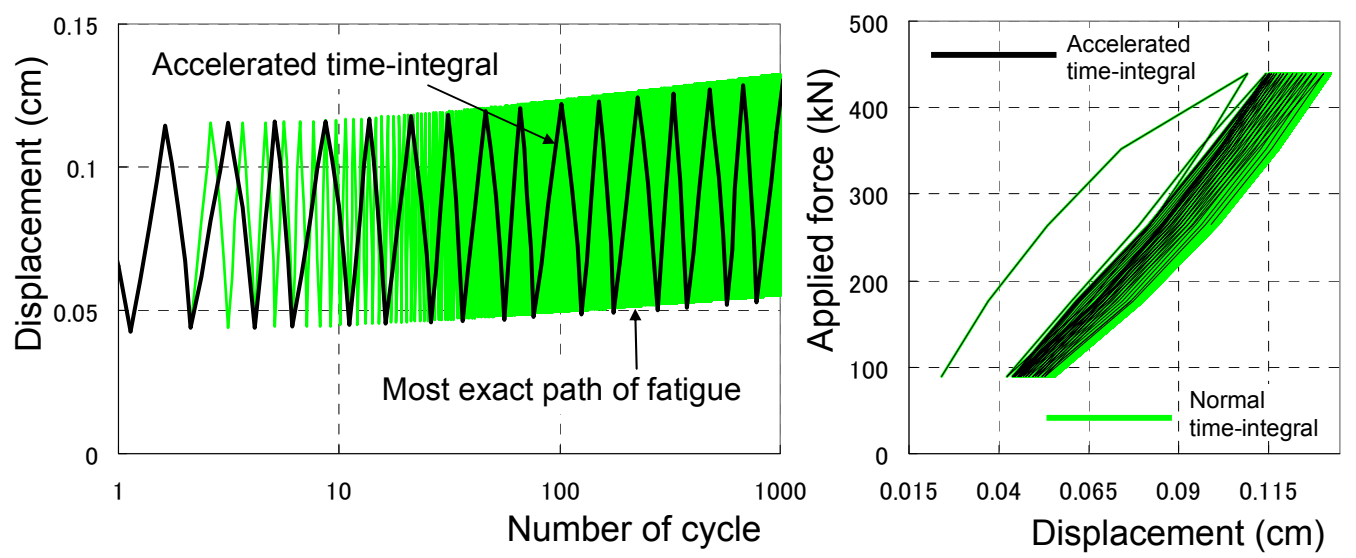

Fig. 17 Magnified direct time- and path-integral.
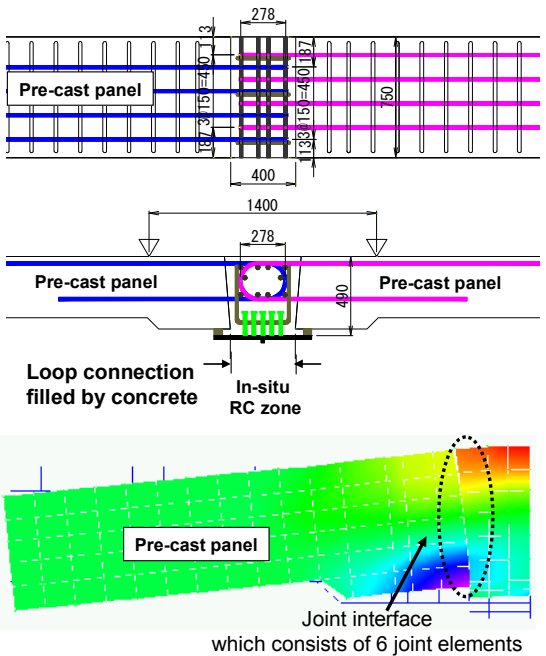
Finite elements and magnified mode of deformation
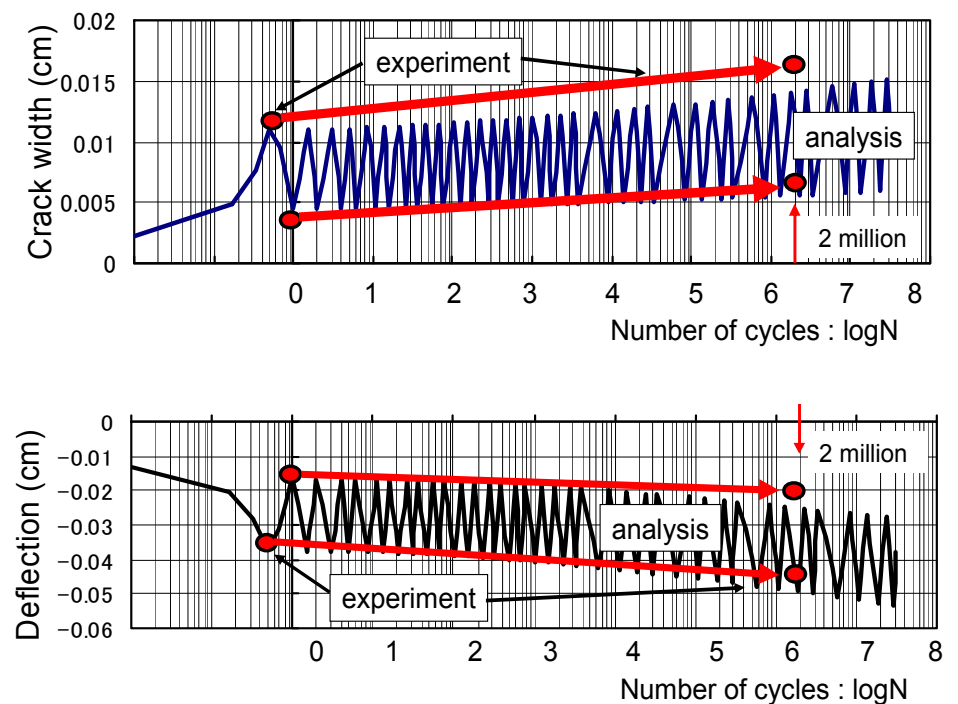

Fig. $18 \mathrm{RC}$ joint interface subjected to combined bending and shear.

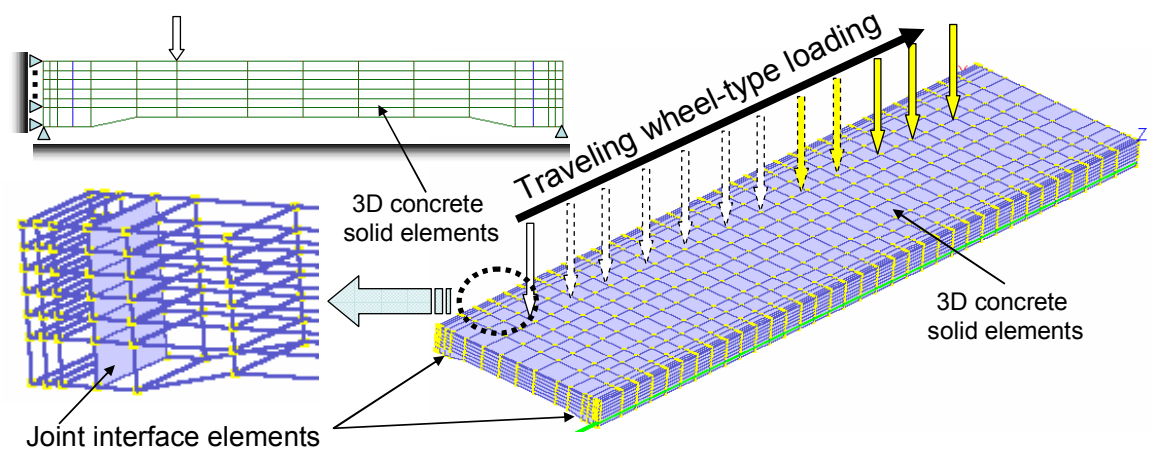

Fig. 19 Structural finite element modeling and boundary conditions.

in practice. Quite reasonably, this behavior appears to be the opposite of that exhibited by statically determinate structural systems, where stiffness decay resulting from fatigue directly causes shear deformation of beam webs (Ueda and Okamura 1982).
Figure 21 shows simulation results for the same panel system but with a constant membrane axial tension applied. This loading is analogous to the selfequilibrated sectional force induced by thermal action, assuming that the panel system is firmly fixed by 
external constraints. Under this severe loading condition, the joint plane is subjected to full tension at any one time and the reinforcement stress is larger than under free membrane action, as shown in Fig. 20. This accelerates the fatigue of both dowel action and bond pullout. In fact, deflection is substantially increased, but the general tendency of overall behavior is similar to the case with no membrane tension. As the external tension is carried by the reinforcement, the tension reinforcement stress at the joint is elevated. At the same time, contact compression produced by the flexure is consistently lower, as shown in Fig. 21. In analysis, the embedment length of reinforcing bars is assumed to be sufficiently long with loop anchorage as shown in Fig. 18.

It is known that the fatigue life of RC slabs under moving wheel loads is much less than the life under fixed point pulsation. The mechanism of this difference in fatigue life has been investigated (Matsui 1987, Perdikaris and Beim 1988) and crack-to-crack interaction is thought to be one of main reasons for the difference (Maekawa et al. 2006). In order to study the fatigue characteristics of the panel system under investigation here, a wheel-type moving load is applied

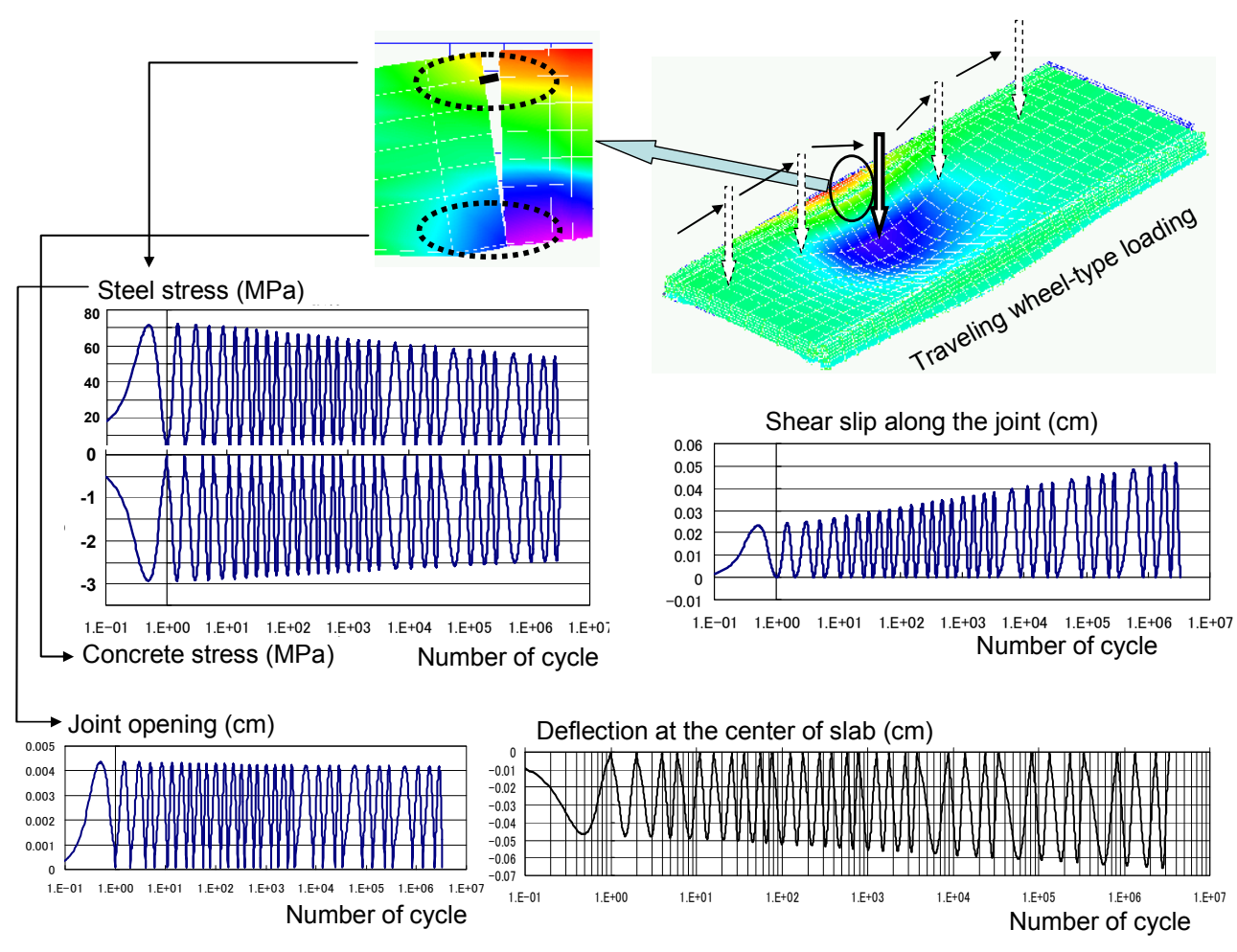

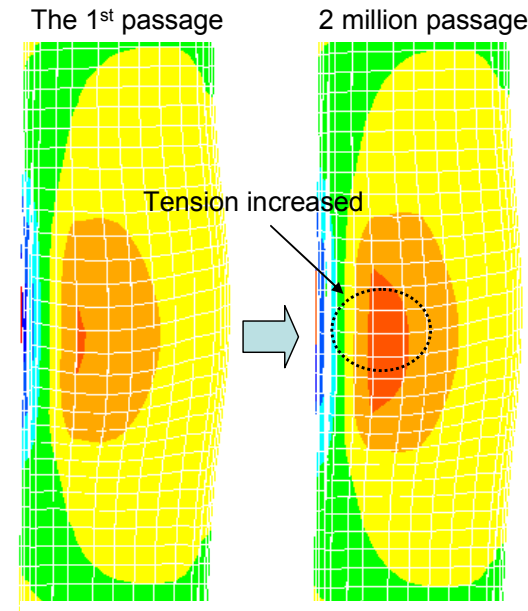

Tensile stress at the bottom face

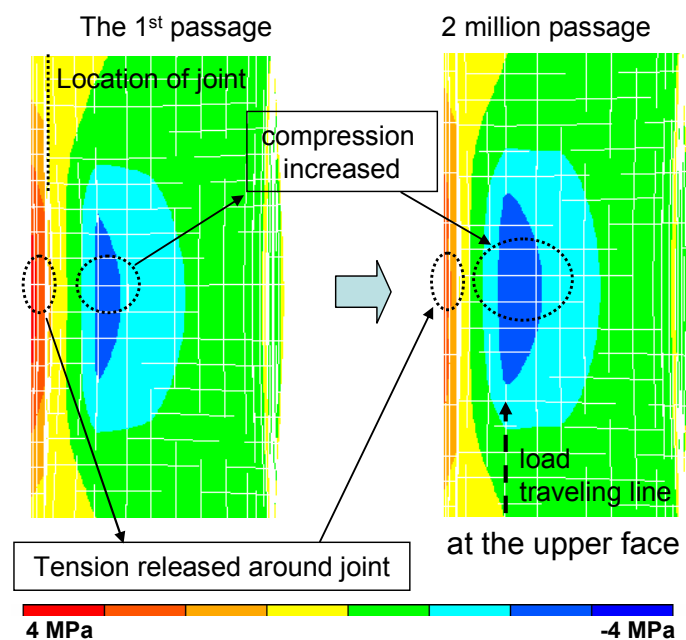

Fig. 20 Fatigue deformation mode and mechanism (dowel action only). 

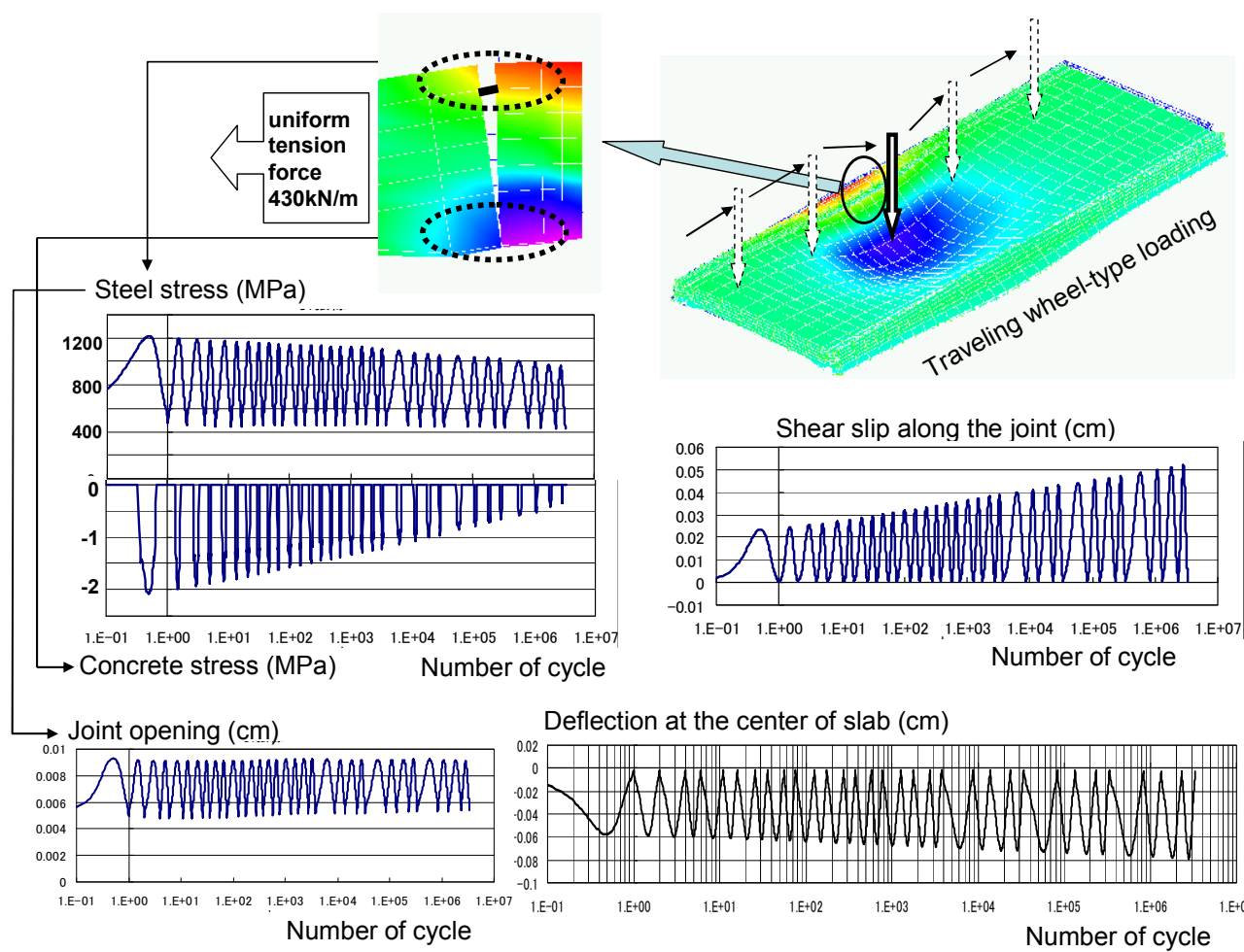

Fig. 21 Fatigue deformation mode and mechanism under membrane tension.
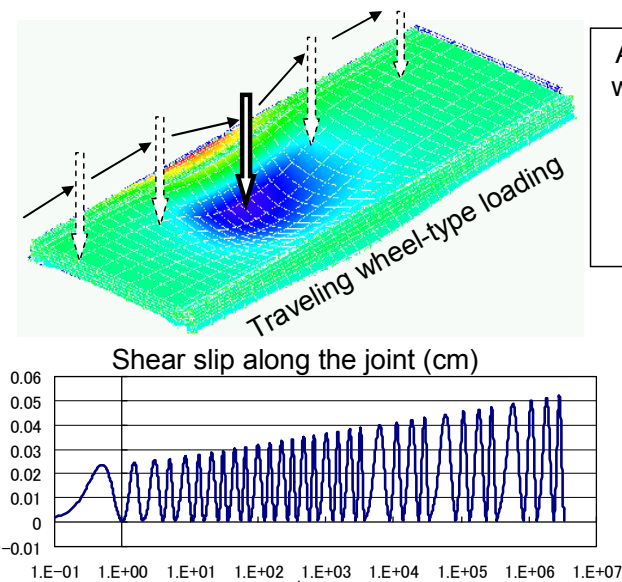

Deflection at the center of slab $(\mathrm{cm})$

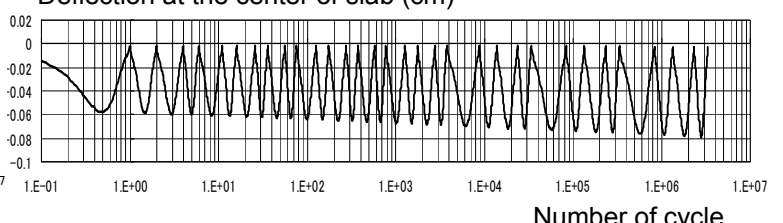

(a) Pre-cast slabs under fixed and moving fatigue loads

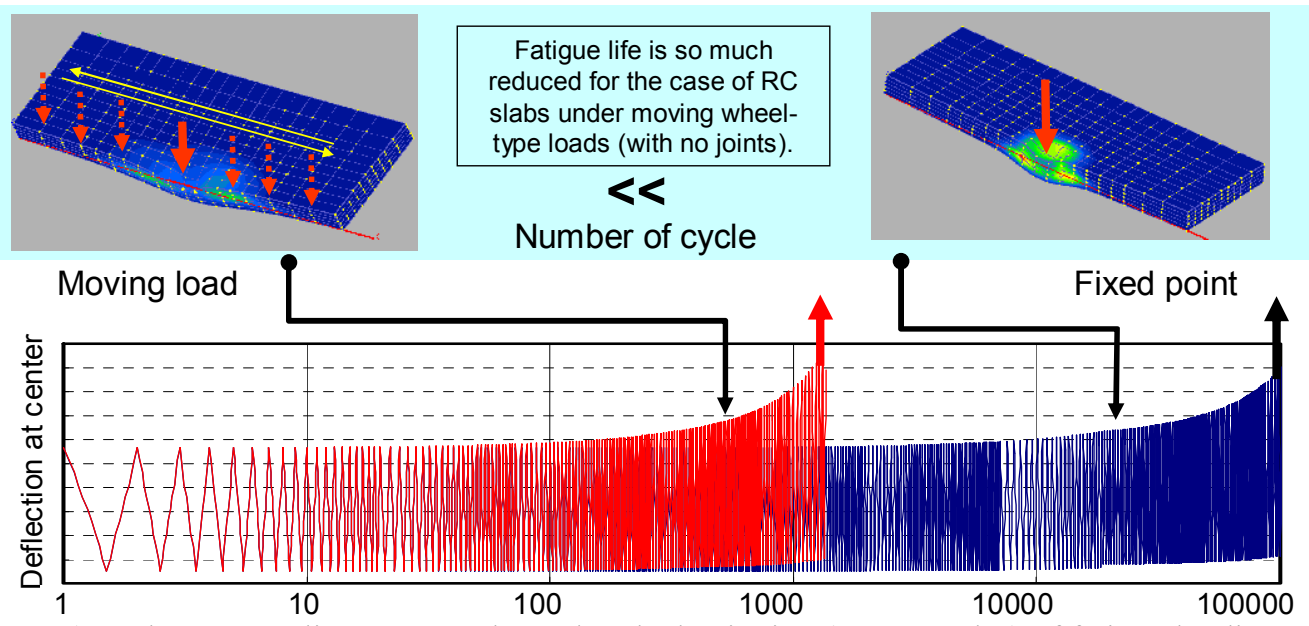

note) Both response lines are overlapped at the beginning (1-100 cycles) of fatigue loading.

(b) Monolithically constructed slabs under fixed and moving fatigue loads (Maekawa, et al. 2006)

Fig. 22 Effect of loading patterns and comparison with RC slabs with multi-directional cracking. 
to the upper surface of the assembled slab system. Figure 22 compares the progress of deflection under fixed point as well as moving wheel loading. At the extreme end of fatigue life, dramatic increment of deflection is experienced and no dynamic equilibrium solution can be found in the predictor-corrector method. There is a fair coincidence between the two. This is very different from the behavior of monolithic RC slabs. The main point is that crack location and the mode of joint deformation barely differ.

As a matter of fact, crack location and orientation do not change over the whole life of the structure, even though flexural tension somehow increases in the main pre-cast panels. That is, in contrast with a monolithic PC slab, the mode of deformation does not change. It can be said that this PC-RC mixed structural system has a central portion that is strengthened by pre-stressing and crack nonlinearity is confined solely to the $\mathrm{RC}$ connection units. Since the nonlinearity is structurally confined within a limited range, shear transfer decay provoked by principal stress rotation barely occurs. Here, the concrete that confines the reinforcement at joints is assumed to be rather massive without spalling of the concrete cover nor splitting cracks along the reinforcing steel. For more general cases, the dowel action model needs to be more generalized (Vintzeleou and Tassios 1987). As these fatigue analyses on wheel type traveling loads are also time-dependent, the delayed recovery of deflection after passage of wheel loads is consequentially computed. This effect was checked by changing the traveling speed of wheels, and negligibly small influence was confirmed for these cases at the preliminary stage of this study.

\section{Conclusions}

(1) The direct path integral scheme for fatigue loading, which has been previously verified for 3D smeared crack fields, was applied to joint interfaces subjected to high cycle load repetition. Its applicability was confirmed experimentally and computationally.

(2) A fatigue model for the bond pullout of reinforcement embedded in massive concrete was presented. The fatigue-induced reduction in pullout stiffness can be represented in terms of equivalently evolved bond deterioration close to the free surface of the joints.

(3) The cyclic fatigue of dowel steel bars was experimentally investigated by the use of push-off specimens, and the development of greater dowel shear was noted. The reduced stiffness corresponding to lower transverse dowel shear is simply idealized using a stiffness reduction factor to represent the degradation of the surrounding concrete. This mechanism was incorporated into the framework of the joint interface with shear transfer models of joint contact.
(4) An experimental verification of general joint interface elements was performed under nonuniform stress and strain fields with regard to combined bending and shear. The applicability of the model was confirmed here as well as in the case of a uniform stress field.

(5) Logarithmic time-integration for accelerated computation was put to the test and its functionality was ascertained.

(6) The proposed finite element computation method for fatigue was applied to a full three-dimensional model of a pre-cast slab assembly subjected to moving loads and its computational feasibility was confirmed. Further enhancement and generalization of the material models used for the joint interfaces may directly contribute to improved fatigue simulation of structural concrete in general.

\section{Acknowledgments}

The authors express their gratitude to Dr. K. Suda of Kajima Corporation for valuable discussions related to joint fatigue experiments. The analytical study was carried out using the $3 \mathrm{D}$ structural analysis program COM3 (COncrete Model for 3D), whose enhancement was financially supported by Grant-in-Aid for Scientific Research (S) No.15106008. The fatigue experiment for dowel action and the application of the simulation to pre-cast structural systems were promoted by a Research Grant from The Ministry of Land and Transport of The Japanese Government in 2006.

\section{References}

Atimtay, E. and Ferguson, P. M. (1973). "Early chloride corrosion of reinforced concrete - A test report." $A C I$ Journal, 70(9), 606-613.

Carol, I., Prat, P. C. and Lopez, C. M. (1997). "Normal/shear cracking model: application to discrete crack analysis." Journal of Engineering Mechanics, 123(8), 765-773.

Collins, M. P. and Vecchio, F. (1982). "The response of reinforced concrete to in-plane shear and normal stresses." University of Toronto.

Frenaij, J. W. I. J., Walraven, J. C. and Reinhardt, H. W. (1988). "Time-dependent shear transfer in cracked reinforced concrete." Delft University Press.

Gebreyouhannes, E. (2006). "Shear transfer behavior of cracked concrete under fatigue loading." 6th International PhD Symposium in Civil Engineering, Zurich, 40-42.

Japan Society of Civil Engineers (2002). "Standard specification of concrete structures - Structural performance verification -".

Li, B. and Maekawa, K. (1987). "Contact density model for cracks in concrete." IABSE Colloquium, Delft, 51-62, or Journal of the Faculty of Engineering, The University of Tokyo (B), XL(1).

Lotfi, H. R. and Shing, P. B. (1994). "Interface model 
applied to fracture of masonry structures." Journal of Structural Engineering, 120(1), 63-80.

Maekawa, K., Toongoenthong, K., Gebreyouhannes, E. and Kishi, K. (2006). "Direct path-integral scheme for fatigue simulation of reinforced concrete in shear." Journal of Advanced Concrete Technology, 4(1), 159-177.

Maekawa, K., Gebreyouhannes, E., Mishima, T. and An, X. (2006). "Three-dimensional fatigue simulation of RC slabs under traveling wheel-type loads." Journal of Advanced Concrete Technology, 4(3), 445-457.

Maekawa, K, Pimanmas, A. and Okamura, H. (2003). "Nonlinear Mechanics of Reinforced Concrete." Spon Press, London.

Maekawa, K. and Qureshi, J. (1996). "Computational model for reinforcing bar embedded in concrete under combined axial pullout and transverse displacement." Proc. of JSCE, 538/V-31.

Mattock, A. H. and Hawkins, N. M. (1972). "Shear transfer in reinforced concrete-recent research." Journal of PCI, 17 (2), 55-75.

Nakasu, M. and Iwatate, J. (1996). "Fatigue experiment on bond between concrete and reinforcement." Transaction of JSCE, V-426, 852-853.

Matsui, S. (1987). "Fatigue strength of RC-slabs of highway bridge by wheel running machine and influence of water on fatigue." Proc. of JCI, 9(2), 627-632.

Okamura, H. and Maekawa, K. (1991). "Nonlinear analysis and constitutive models of reinforced concrete." Giho-do Press, Tokyo.

Palmgren, A. G. (1924). "Die Lebensdauer von Kugellagern." VDI-Zeitschrift des Vereines Deutscher Ingenieure, 68(14), 339-341.

Perdikaris, P. C. and Beim, S. R. (1988). "RC bridge decks under pulsating and moving load." Journal of Structural Engineering, ASCE, 114(3), 591-607.

Poli, S. D., Prisco, M. D. and Gambarova, P. G. (1992). "Shear response, deformations and subgrade stiffness of a dowel bar embedded in concrete." ACI Structural Journal, 89(6), 665-675.

Pruijssers, A. F., Walraven, J. C. and Reinhardt, H. W.
(1988). "Aggregate interlock and dowel action under monotonic and cyclic loading." Delft University Press.

Shima, H., Chou, L. and Okamura, H. (1987). "Micro and macro models for bond in reinforced concrete." Journal of the Faculty of Engineering, The University of Tokyo (B), 39(2), 133-194.

Shin, H., Maekawa, K. and Okamura, H. (1988). "Analytical approach of RC members subjected to reversed cyclic in-plane loading." Proc. of JCI Colloquium on Ductility of Concrete Structures and its Evaluation, 2, 45-46.

Soltani, M. and Maekawa, K. (2007). "Path-dependent mechanical model for deformed reinforcing bars at $\mathrm{RC}$ interface under coupled cyclic shear and pullout tension." Engineering Structures, Elsevier.

Soroushian, P., Obaseki, K., Baiyasi, M. I., El-Sweidan, B. and Choi, K.-B. (1988). "Inelastic cyclic behavior of dowel bars." ACI Structural Journal, 85(1), 23-29.

Taira, Y., Suda, K., Aikawa, K. and Noguchi, T. (2007). "Cyclic fatigue loading experiment of connection joints in between pre-cast panels." Transaction of Japan Society of Civil Engineers, V.

Tassios, T. P. and Vbintzeleou, E. N. (1987). "Concreteto-concrete friction, Journal of Structural Engineering." ASCE, 113(4), 832-849.

Ueda, T. and Okamura, H. (1982). "Fatigue behavior of reinforced concrete beams under shear force." IABSE Colloquium (Lausanne), 415-422.

Vintzeleou, E. N. and Tassios, T. P. (1987). "Behavior of dowels under cyclic deformations." ACI Structural Journal, 84(1), 18-30.

Walraven, J. C. (1981). "Fundamental analysis of aggregate interlock." Journal of Structural Division, ASCE, 107(ST11), 2245-2270.

Walraven, J. C. and Reinhardt, H. W. (1981). "Theory and experiments on the mechanical behavior of crack in plain and reinforced concrete subjected to shear loading," HERON, 26(1A), 5-68.

Yamada, K., Shima, H. and Haraguchi, K. (1991). "Effects of cyclic loading and time on bond between steel bar and concrete." Proc. of Japan Concrete Institute, 13(2), 133-138. 